\title{
In-Hospital Outcomes after Radical Cystectomy for Bladder Cancer: Comparing National Trends in the United States and Germany from 2006 to 2014
}

\author{
Christer Groeben $^{\mathrm{a}}$ Rainer Koch ${ }^{\mathrm{b}}$ Martin Baunacke ${ }^{\mathrm{a}}$ Angelika Borkowet $^{\mathrm{a}}$ \\ Manfred P. Wirth ${ }^{\mathrm{a}}$ Johannes Huber ${ }^{\mathrm{a}}$

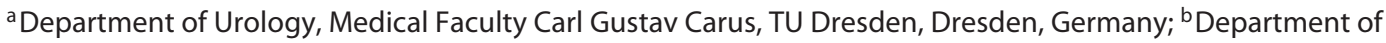 \\ Medical Statistics and Biometry, Medical Faculty Carl Gustav Carus, TU Dresden, Dresden, Germany
}

\section{Keywords}

Radical cystectomy · Bladder cancer · Population-based analysis $\cdot$ Outcomes $\cdot$ Health services research

\begin{abstract}
Background: Radical cystectomy (RC) still poses a significant risk for mortality and morbidity. Objectives: We compared in-hospital outcomes after RC in the United States and Germany using population-based data. Methods: We compared data from the US Nationwide Inpatient Sample to the German hospital billing database. Mortality and transfusion during hospital stay and length of stay (LOS) were evaluated. Results: In all, 17,711 (the United States) and 60,447 (Germany) cases were included. The share of robot-assisted RC increased to $20.5 \%$ in the United States vs. $2.3 \%$ in Germany $(p<0.001)$. In-hospital mortality was $1.9 \%$ (the United States) vs. $4.6 \%$ (Germany), transfusion rates were $34.2 \%$ (the United States) vs. $58.7 \%$ (Germany), and LOS was 10.7 (the United States) vs. 25.1 days (Germany; all $p<0.001$ ). On multivariate analysis, higher patient age and lower annual hospital caseload were associated with increased mortality and longer LOS. Minimalinvasive surgery was associated with less blood transfusion and shorter LOS in the United States vs. hospital caseload and
\end{abstract}

\section{KARGER}

() 2019 S. Karger AG, Basel

E-Mail karger@karger.com

www.karger.com/uin choice of urinary diversion in Germany. Conclusions: Healthcare systems might exert a relevant impact on outcomes of oncologic surgery. Increased in-hospital mortality rates in Germany seem to be partly explained by much longer LOS compared to those in the United States. Annual caseload seems to be influential on in-hospital outcomes raising the question of centralization of RC.

(c) 2019 S. Karger AG, Basel

\section{Introduction}

With a yearly incidence of 77,000 in the United States and 30,000 in Germany, bladder cancer poses a major burden on the population $[1,2]$. For patients with muscle-invasive or superficial treatment-refractory cancer radical cystectomy $(\mathrm{RC})$ remains the gold standard. The morbidity and mortality are among the highest in oncological surgery [3-7]. Influential factors are the high level of invasiveness combined with patient-derived factors such as the elevated mean patient's age and greater comorbidity $[4,6,8,9]$.

Improvements in perioperative care, anesthesia, and surgical technique have led to a decrease in postoperative 
mortality with rates from $20 \%$ in the late 1970 s to currently between 2.5 and $7.9 \%[3,5]$. Higher surgical volume is associated with improved outcomes [7, 10-13], but the magnitude of this effect remains controversial. While several studies emphasize the importance of the surgeon's experience [7], the influence of treating institution and perioperative management might be additional key factors to reduce in-hospital morbidity and mortality $[10,11,13]$. The introduction of laparoscopic RC (LRC) and later robot-assisted RC (RARC) has achieved less blood loss, wound infections, and a shorter length of hospital stay (LOS) compared to open RC (ORC) in several single-center studies $[5,14]$. However, a randomized controlled trial failed to identify a large advantage for RARC [15].

The United States and Germany entertain very diversely developed and organized health care systems [16]. To this day, no studies about outcomes of RC in Germany exist on a total population level and there are no studies comparing RC outcomes between large western healthcare systems.

The aim of the study is to fill this gap and to compare recent trends of in-hospital mortality, blood transfusion rates, and LOS after RC in the United States and Germany.

\section{Materials and Methods}

US Nationwide Inpatient Sample

To obtain data of RCs in the United States, we utilized the Nationwide Inpatient Sample (NIS) covering the years 2006-2014 provided by the Healthcare Cost and Utilization Project. The NIS comprises a representative $20 \%$ sample of all hospital admissions in the United States. The relevant patient cohort was identified similar to our previously described method [17]. Inclusion criteria were the diagnosis of a bladder neoplasm in combination with a coded procedure of RC and a minimum age of 18 at surgery. Analyses involving hospital caseload are restricted to the years 20062011.

\section{German Billing Database}

The German Federal Statistical Office entertains a nationwide billing database. For the purpose of this study the data is virtually complete. Cohort identification and data extraction were performed accordingly and similarly to previously described methods [11].

Please refer to the online supplement for further details.

\section{Statistics}

We extracted the absolute number of cases and calculated rates for mortality and blood transfusion. Results were stratified for age, gender, type of urinary diversion (UD), surgical approach, and annual hospital caseload. We applied linear models for LOS, and logistic models for in-hospital mortality and blood transfusion. To detect trends over time, linear regression was implemented. We compared rates, means and trends using Waldtests. A value level of $p<0.05$ was regarded as significant. We used SAS 9.4 (SAS Institute GmbH, Heidelberg, Germany) for all analyses.

\section{Results}

Seventeen thousand seven hundred and eleven cases from the NIS database were included with a varying annual total caseload between 1,666 in 2006 and 2,009 in 2014. From the German billing database 60,447 cases of RC with bladder cancer were extracted. Annual caseload increased continuously from 5,627 in 2006 to 7,390 in 2014. Patient characteristics and patterns of care are presented in Table 1. The mean age of patients in the United States remained stable at $68.2 \pm 10.5(p=0.9)$ years while increasing in Germany from $68.0 \pm 9.6$ to $69.4 \pm 9.9(p<$ 0.001 ) years ( $p<0.001$ for trend comparison).

\section{Caseload Distribution (2006-2011)}

Figure 1 gives an overview of the caseload distribution. The majority of US hospitals served low annual caseloads $<4$ cases with a decreasing respective share of patients from 16.5 to $10.5 \%(p=0.019)$ and an increasing share for high volume hospitals ( $>50$ cases) from 4.1 to $41.5 \%$ ( $p=0.004)$. In Germany, the shares of RC in low and high volume hospitals remained stable at $0.9 \%(p=$ $0.9)$ and $14.1 \%$ respectively $(p=0.2)$.

Figure 2 demonstrates the development of surgical approaches in both countries. The share of LRC remained stable in the United States $(p=0.6)$ while increasing for RARC from 0.7 to $20.5 \%(p<0.001)$, and decreasing for ORC from 99.7 to $79.1 \%(p<0.001)$. In Germany, LRC increased from 0.7 to $1.5 \%(p<0.001)$ and RARC from 0 to $2.3 \%(p<0.001)$, while ORC decreased from 99.3 to 96.2\% $(p<0.001)$.

\section{In-Hospital Mortality}

In-hospital mortality was $1.9 \%$ in the United States vs. $4.6 \%$ in Germany $(p<0.001)$. Mortality rates differed for different surgical approaches in the United States (LRC $1.6 \%$ vs. RARC $1.1 \%$ vs. ORC $2.0 \% ; p=0.003)$ and Germany (LRC $3.4 \%$ vs. RARC $2.4 \%$ vs. ORC $4.6 \%$; $p<$ $0.001)$. Higher annual caseloads were associated with lower mortality in the United States $(<4$ cases $3.6 \%$ vs. $4-10$ cases $2.4 \%$ vs. $11-25$ cases $2.6 \%$ vs. $26-50$ cases $1.2 \%$ vs. $>50$ cases $1.5 \% ; p<0.001)$ and Germany $(<4$ cases $6.7 \%$ 
Table 1. Patient characteristics and patterns of care of RC in the United States and Germany (years 2006-2011)

\begin{tabular}{lccc}
\hline & United States & Germany & $p$ value \\
\hline Total number of patients, $n$ & 11,837 & 38,516 & \\
Gender, $n(\%)$ & & & \\
$\quad$ Male & $9,038(76.4)$ & $28,817(74.8)$ & 0.0007 \\
Age, years, mean \pm SD & $68.2 \pm 10.5$ & $68.8 \pm 9.9$ & $<0.0001$ \\
Annual hospital caseload, $n(\%)$ & & & $<0.0001$ \\
$\quad 0-3$ & $1,508(12.7)$ & $381(1.0)$ & \\
$\quad 4-10$ & $2,733(23.1)$ & $3,868(10.0)$ & \\
$\quad 11-25$ & $2,676(22.6)$ & $16,217(42.1)$ & $<0.0001$ \\
$\quad 1,776(15.0)$ & $12,837(33.3)$ & $<0.0001$ \\
$\quad$ >50 & $3,144(26.6)$ & $5,231(13.6)$ & \\
Teaching status, $n(\%)$ & $8,846(74.7)$ & $7,444(19.3)$ & \\
$\quad$ Academic & & & \\
Size of hospital, $n(\%)$ & $1,070(9.0)$ & $6,058(15.7)$ & $<0.0001$ \\
$\quad$ Small & $1,897(16.0)$ & $17,838(46.3)$ & \\
$\quad$ Medium & $8,870(75.0)$ & $14,620(38.0)$ & \\
$\quad$ Large & & & \\
Hospital location, $n(\%)$ & $11,452(96.7)$ & $34,105(88.5)$ & \\
$\quad$ Urban & $385(3.3)$ & $4,411(11.5)$ & \\
$\quad$ Rural & & & \\
\hline RC, radical cystectomy. & & & \\
\hline
\end{tabular}

vs. $4-10$ cases $5.0 \%$ vs. $11-25$ cases $5.0 \%$ vs. $26-50$ cases $4.1 \%$ vs. $>50$ cases $3.3 \%$; $p=0.002$ ).

On multivariate analysis (Table 2) in the United States increasing age and lower annual hospital caseload were the most important risk factors for in-hospital mortality. In Germany, increasing age, lower annual hospital caseload, and the type of UD had the highest impact.

\section{Blood Transfusion}

The overall rate of blood transfusion in the United States was 34.2 vs. $58.7 \%$ in Germany $(p<0.001)$ with a significant decrease in Germany from 61.1 to $52.4 \%$ ( $p=$ 0.002 ). The transfusion rate concerning surgical approach in the United States was 38.1\% for LRC, 23.3\% for RARC and $35.9 \%$ for ORC ( $p=0.012)$. In Germany, transfusion rates were $48.4 \%$ for LRC, $33.6 \%$ for RARC and $59.2 \%$ for ORC $(p<0.001)$. Low annual caseloads were also associated with higher rates of blood transfusion in the United States ( $<4$ cases $42.1 \%$ vs. $4-10$ cases $35.6 \%$ vs. $11-25$ cases $35.7 \%$ vs. $26-50$ cases $31.4 \%$ vs. $>50$ cases $36.5 \%$; $p<0.001$ ) and Germany ( $<4$ cases $63.2 \%$ vs. $4-10$ cases $64.0 \%$ vs. $11-$ 25 cases $59.7 \%$ vs. $26-50$ cases $58.9 \%$ vs. $>50$ cases $51.4 \%$; $p<0.001)$.

Multivariate analysis (Table 2) indicated open surgery followed by female gender and hospital size to be the most influential factors for blood transfusion in the United
States, while in Germany, this were female gender followed by higher age. Open surgery, choice of UD, and low hospital caseload were additional relevant covariates.

\section{Length of Stay}

The overall LOS for RC decreased in the United States from $11.3 \pm 8.1$ to $9.7 \pm 7.4$ days $(p<0.001)$ and in Germany from $26.8 \pm 14.6$ to $24.2 \pm 15.4$ days $(p<0.001 ; p=0.084$ for comparison of trends). In the United States, LOS was longer for LRC with $12.3 \pm 13.5$ vs. $8.7 \pm 5.7$ (RARC) and $10.9 \pm 8.8$ days for ORC ( $p=0.004)$. In Germany, LRC also entailed the longest LOS with $25.4 \pm 21.5$ vs. $21.5 \pm 12.7$ (RARC) and ORC with $25.2 \pm 14.6$ days $(p<0.001)$. High-volume hospitals presented shorter LOS in the United States $(<4$ cases $11.4 \pm 8.8$ vs. $4-10$ cases $10.8 \pm 8.1$ vs. $11-25$ cases $10.8 \pm 9.1$ vs. $26-50$ cases $9.8 \pm 7.1$ vs. $>50$ cases $10.3 \pm 9.2$ days $p<$ $0.001)$ and in Germany ( $<4$ cases $24.5 \pm 12.1$ vs. $4-10$ cases $26.3 \pm 15.6$ vs. $11-25$ cases $26.1 \pm 14.6$ vs. $26-50$ cases $24.7 \pm$ 14.4 vs. $>50$ cases $23.3 \pm 13.8$ days; $p=0.036$ ).

Multivariate analysis (Table 3 ) of the US data indicated hospital caseload to be the most important factor for LOS followed by surgical approach, age of patients, and choice of UD. In Germany surgical approach had no significant influence, while choice of UD and hospital caseload had a high impact. Teaching status, gender, and age were factors that were less influential. 


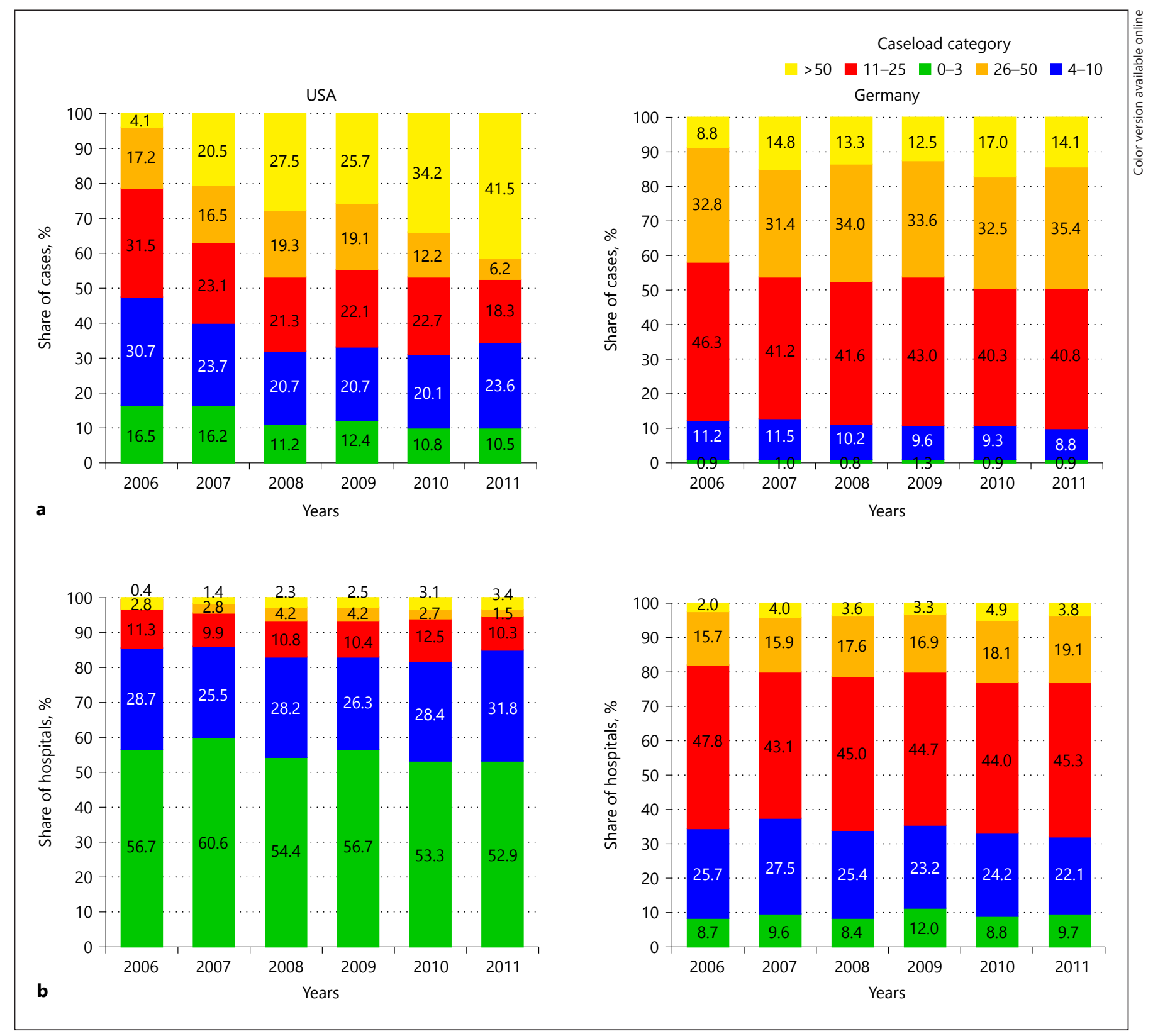

Fig. 1. Distribution of RC patients (a) and share of hospitals performing RC (b) in the United States and Germany stratified for annual hospital caseload for the years 2006-2011.

\section{Discussion}

In-hospital mortality, blood transfusion rates, and the LOS were considerably lower in the United States than in Germany. Multivariate models indicated patient age and annual hospital caseload to be important factors for mortality and LOS in both countries. In the United States, surgical approach had a significant influence on transfusion and the LOS, while in Germany, most influ- ential factors were hospital caseload and the choice of UD.

RARC is a well-established alternative to ORC in the United States with constantly inclining numbers while the magnitude of this trend is not seen in Germany. This development is in line with the slower implementation of robot-assisted surgery for other indications in Germany $[18,19]$. This might be due to the lack of additional reimbursement for the use of a surgical robot due to the prin- 


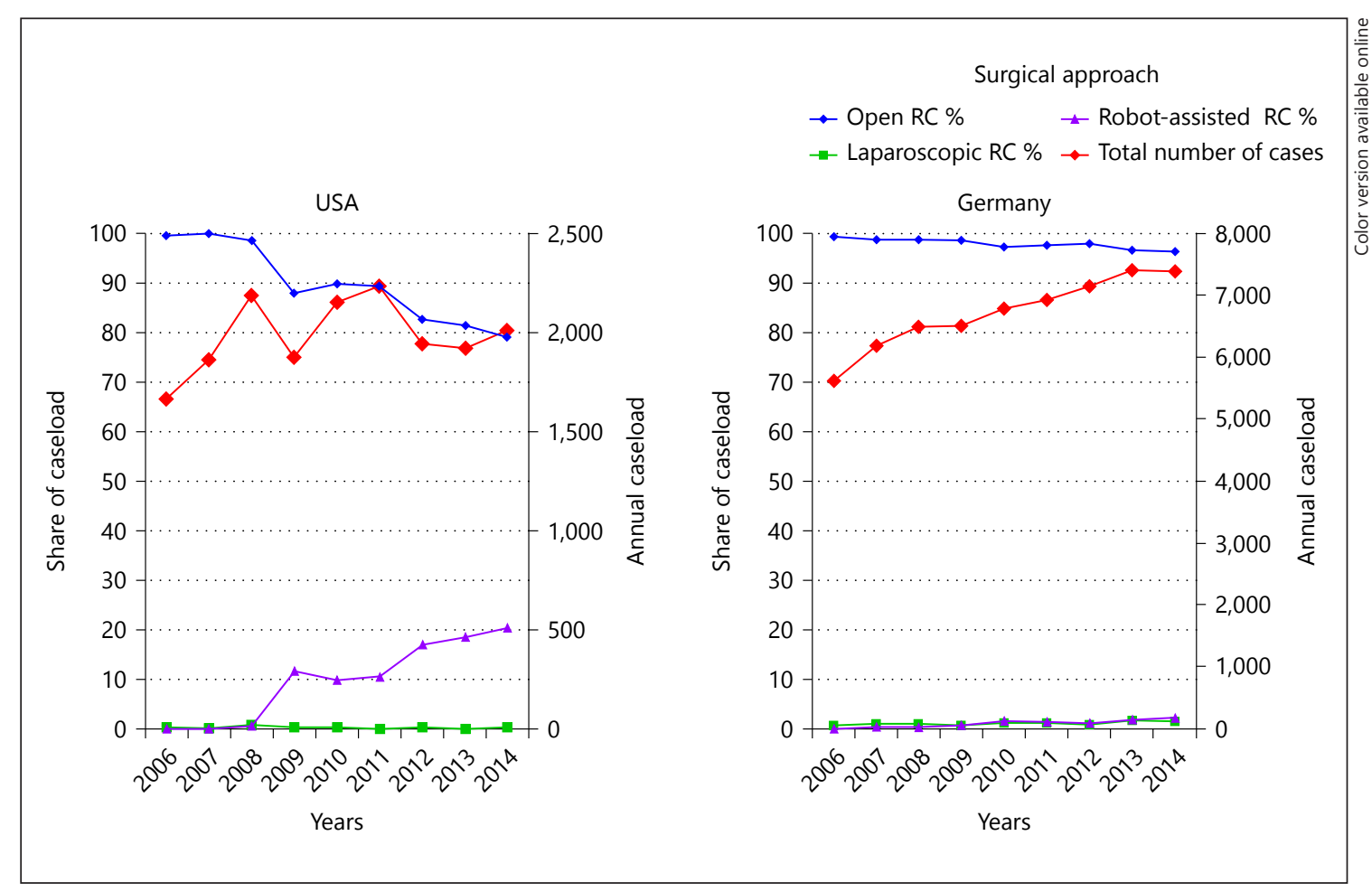

Fig. 2. Surgical approach and absolute number of RC in the United States (NIS $20 \%$ national sample) and Germany. RC, radical cystectomy.

ciple of cost containment in German healthcare policy $[16,17]$. A growing body of evidence shows advantages of RARC concerning decreased blood loss and wound infections and shorter LOS $[5,14]$. This is confirmed by our multivariate models. In univariate analysis, in-hospital mortality rates were also lower after RARC in both countries. Obviously, clinical case selection might explain these differences.

In-hospital mortality in the United States was less than half of the German rate (2.2 vs. $4.6 \%$ ). This difference is largely explained by the shorter time of observation, since LOS in the United States was also less than half that in Germany (10.7 vs. 25.2 days). When comparing current 30 - or 90-day mortality rates from the literature, the difference between the 2 countries appears negligible [3, 7 , 13]. Additionally, the mean age of RC patients in Germany is higher and constantly inclining in Germany [4, 6], while older age proved to be the most important risk factor for in-hospital mortality in both countries followed by annual caseload. In Germany, incontinent UD also showed significant influence. The missing influence for the US data might not be seen due to higher rates of incontinent UD (USA 93 vs. $71 \%$ Germany in 2014). Since almost every patient received incontinent UD in the
United States, the clinical selection of older and frailer patients is likely to be masked [17]. Although these results imply a careful selection of older patients for RC, current studies showed acceptable rates of complications and mortality when older patients were treated in surgical centers [9].

Age, sex, and minimal invasive RC were influential factors for blood transfusion in both countries. Thus, explanations for the significant difference in transfusion rates must be seen in higher average age, a greater share of female patients, and much lower use of RARC in Germany. Additionally, we assume differences in clinical practice, although this is not supported by respective national guidelines [20,21]. Despite declining transfusion rates in Germany, more restrictive regimens might be required.

Older age and lower annual caseload increased the LOS in both countries, which is in line with existing literature [6]. Fundamental differences in concepts of perioperative care must be taken into account when assessing the marked difference in LOS between the United States and Germany. The German healthcare system is publicly financed with legal obligation to health care insurance and almost universal coverage of health care expenses. 
Table 2. Logistic models of the prognostic factors for the probability of mortality or blood transfusion during the hospital stay following RC in Germany and the United States of the years 2006-2011

\begin{tabular}{|c|c|c|c|c|c|c|c|c|}
\hline \multirow[t]{3}{*}{ Variable } & \multicolumn{4}{|l|}{ United States } & \multicolumn{4}{|l|}{ Germany } \\
\hline & \multicolumn{2}{|l|}{ mortality } & \multicolumn{2}{|l|}{ transfusion } & \multicolumn{2}{|l|}{ mortality } & \multicolumn{2}{|l|}{ transfusion } \\
\hline & OR $(95 \% \mathrm{CI})$ & $p$ value & OR $(95 \% \mathrm{CI})$ & $p$ value & OR $(95 \% \mathrm{CI})$ & $p$ value & OR $(95 \% \mathrm{CI})$ & $p$ value \\
\hline \multicolumn{9}{|c|}{ Individual surgery performed as laparoscopy or robot-assisted } \\
\hline No & $1.44(0.74-2.83)$ & 0.2854 & $1.70(1.43-2.03)$ & $<0.0001$ & $0.89(0.60-1.31)$ & 0.5430 & $1.97(1.76-2.20)$ & $<0.0001$ \\
\hline Yes (reference) & 1 & - & 1 & - & 1 & - & 1 & - \\
\hline \multicolumn{9}{|l|}{ Urinary diversion } \\
\hline Incontinent & $1.40(0.71-2.76)$ & 0.3374 & $1.02(0.88-1.23)$ & 0.8075 & $2.04(1.78-2.34)$ & $<0.0001$ & $1.61(1.55-1.68)$ & $<0.0001$ \\
\hline Continent (reference) & 1 & - & 1 & - & 1 & - & 1 & - \\
\hline \multicolumn{9}{|l|}{ Annual hospital caseload } \\
\hline $0-3$ & $2.26(1.41-3.62)$ & 0.0007 & $1.15(0.99-1.33)$ & 0.0704 & $2.16(1.37-3.40)$ & 0.0010 & $1.62(1.34-1.95)$ & $<0.0001$ \\
\hline $4-10$ & $1.51(1.00-2.28)$ & 0.0482 & $0.92(0.81-1.03)$ & 0.1418 & $1.53(1.20-1.94)$ & 0.0005 & $1.48(1.37-1.60)$ & $<0.0001$ \\
\hline $11-25$ & $1.58(1.08-2.31)$ & 0.0188 & $0.97(0.87-1.08)$ & 0.5374 & $1.22(1.22-1.81)$ & $<0.0001$ & $1.28(1.20-1.36)$ & $<0.0001$ \\
\hline $26-50$ & $0.78(0.47-1.30)$ & 0.3374 & $0.82(0.72-0.93)$ & 0.0021 & $1.03(1.03-1.50)$ & 0.0253 & $1.02(0.97-1.08)$ & 0.8091 \\
\hline $50+($ reference $)$ & 1 & - & 1 & - & 1 & - & 1 & - \\
\hline \multicolumn{9}{|l|}{ Teaching Status } \\
\hline Non-academic & $0.95(0.69-1.31)$ & 0.7445 & $0.96(0.87-1.07)$ & 0.4627 & $1.05(0.88-1.24)$ & 0.5969 & $1.36(1.27-1.41)$ & $<0.0001$ \\
\hline Academic(reference) & 1 & - & 1 & - & 1 & - & 1 & - \\
\hline \multicolumn{9}{|l|}{ Size of the hospital } \\
\hline Small & $0.59(0.36-0.99)$ & 0.0457 & $1.49(1.31-1.69)$ & $<0.0001$ & $0.93(0.78-1.12)$ & 0.4582 & $0.75(0.70-0.79)$ & $<0.0001$ \\
\hline Medium & $1.09(0.80-1.51)$ & 0.5792 & $1.19(1.07-1.32)$ & 0.0016 & $1.14(0.99-1.31)$ & 0.6721 & $0.90(0.86-0.94)$ & 0.0159 \\
\hline Large (reference) & 1 & - & 1 & - & 1 & - & 1 & - \\
\hline \multicolumn{9}{|l|}{ Gender } \\
\hline Female & $1.07(0.81-1.41)$ & 0.6367 & $1.63(1.49-1.78)$ & $<0.0001$ & $0.81(0.72-0.91)$ & 0.0003 & $2.34(2.25-2.45)$ & $<0.0001$ \\
\hline Male (reference) & 1 & - & 1 & - & 1 & - & 1 & - \\
\hline \multicolumn{9}{|l|}{ Age } \\
\hline$>50$ (reference) & 1 & - & 1 & - & 1 & - & 1 & - \\
\hline $50-59$ & $0.78(0.34-1.80)$ & 0.5644 & $0.90(0.74-1.10)$ & 0.3038 & $1.08(0.71-1.66)$ & 0.7155 & $1.05(0.96-1.15)$ & 0.3182 \\
\hline $60-69$ & $0.88(0.41-1.89)$ & 0.7456 & $1.08(0.90-1.29)$ & 0.4324 & $1.71(1.15-2.54)$ & 0.0078 & $1.25(1.14-1.36)$ & $<0.0001$ \\
\hline $70-79$ & $2.20(1.07-4.55)$ & 0.0330 & $1.27(1.06-1.53)$ & 0.0089 & $2.35(1.59-3.47)$ & $<0.0001$ & $1.48(1.35-1.61)$ & $<0.0001$ \\
\hline $80+$ & $3.01(1.43-6.34)$ & 0.0037 & $1.42(1.17-1.73)$ & 0.0005 & $3.56(2.38-5.32)$ & $<0.0001$ & $2.10(1.90-2.32)$ & $<0.0001$ \\
\hline
\end{tabular}

Statistical significant values are displayed in bold writing. RC, radical cystectomy.

Ambulatory and stationary care is reimbursed by either statutory or privately financed sickness funds. The statutory sickness funds are nonprofit organizations and the respective contributions by the insured are linked to the annual income. Roughly $10.5 \%$ of German citizens are insured through privately financed sickness funds. Federal, state, and communal governments exert fundamental influence on German health care. For example, health care legislation happens on a federal level, a significant share of hospitals is state or communally owned, and the government supervises the sickness funds and the physician associations.

The US health care system, on the other hand, is less government-regulated and relies more on the concept of the private market. The majority of citizens are privately insured and about one fourth relies on public insurance. Full access to health care for every citizen independent of income is available only since 2010 with the Affordable Care Act. The reimbursement of the health care providers is accomplished mainly by commercial health care providers and to a minor share by federal and state governments on the other hand. Therefore, the financial risk generated by perioperative complications or prolonged hospital stays is distributed differently in both countries. Most German patients do not have to cover any of these costs. However, a relevant share of US patients does, thus making perioperative cost containment an even more desirable goal in the US healthcare system $[16,22]$. Additionally, US healthcare providers themselves are responsible to be cost-efficient leading to reduced postoperative 
Table 3. Linear models of the prognostic factors for the LOS after RC in the United States and Germany with differences (in days) compared to the respective reference (years 2006-2011; SE)

\begin{tabular}{|c|c|c|c|c|c|c|}
\hline \multirow{3}{*}{$\begin{array}{l}\text { Mean length of hospital stay } \\
\text { Variable }\end{array}$} & \multicolumn{3}{|c|}{ United States } & \multicolumn{3}{|l|}{ Germany } \\
\hline & \multicolumn{3}{|c|}{$10.7 \pm 8.6$ days } & \multicolumn{3}{|c|}{$25.1 \pm 14.7$ days } \\
\hline & $\begin{array}{l}\text { Difference, } \\
\text { days }\end{array}$ & SE & $p$ value & $\begin{array}{l}\text { Difference, } \\
\text { days }\end{array}$ & SE & $p$ value \\
\hline \multicolumn{7}{|c|}{ Individual surgery performed as laparoscopy or robot-assisted } \\
\hline No & +1.74 & 0.35 & $<0.0001$ & -0.53 & 0.54 & 0.3273 \\
\hline Yes (reference) & 0 & - & - & 0 & - & - \\
\hline \multicolumn{7}{|l|}{ Urinary diversion } \\
\hline Incontinent & +0.65 & 0.32 & 0.040 & -3.08 & 0.17 & $<0.0001$ \\
\hline Continent (reference) & 0 & - & - & 0 & - & - \\
\hline \multicolumn{7}{|l|}{ Annual hospital caseload } \\
\hline $0-3$ & +2.35 & 0.33 & $<0.0001$ & +1.53 & 0.78 & 0.4994 \\
\hline $4-10$ & +1.12 & 0.26 & $<0.0001$ & +2.97 & 0.34 & $<0.0001$ \\
\hline $11-25$ & 1.23 & 0.24 & $<0.0001$ & +2.31 & 0.26 & $<0.0001$ \\
\hline $26-50$ & -0.13 & 0.27 & 0.6295 & +1.03 & 0.25 & $<0.0001$ \\
\hline $50+($ reference $)$ & 0 & - & - & 0 & - & - \\
\hline \multicolumn{7}{|l|}{ Teaching status } \\
\hline Non-academic & -1.04 & 0.23 & $<0.0001$ & +1.58 & 0.23 & $<0.0001$ \\
\hline Academic (reference) & 0 & - & - & 0 & - & - \\
\hline \multicolumn{7}{|l|}{ Size of the hospital } \\
\hline Small & -0.63 & 0.29 & 0.0234 & -0.98 & 0.26 & 0.0020 \\
\hline Medium & -0.35 & 0.23 & 0.1309 & -0.42 & 0.20 & 0.0409 \\
\hline Large (reference) & 0 & - & - & 0 & - & - \\
\hline \multicolumn{7}{|l|}{ Gender } \\
\hline Female & +0.43 & 0.19 & 0.0230 & +0.96 & 0.17 & $<0.0001$ \\
\hline Male (reference) & 0 & - & - & 0 & - & - \\
\hline \multicolumn{7}{|l|}{ Age } \\
\hline$>50$ (reference) & 0 & - & - & 0 & - & - \\
\hline $50-59$ & -0.47 & 0.41 & 0.2547 & +0.74 & 0.40 & 0.0660 \\
\hline $60-69$ & -0.20 & 0.39 & 0.6023 & +1.75 & 0.38 & $<0.0001$ \\
\hline $70-79$ & +0.85 & 0.39 & 0.0282 & +2.16 & 0.38 & $<0.0001$ \\
\hline $80+$ & +1.65 & 0.42 & $<0.0001$ & +2.85 & 0.42 & $<0.0001$ \\
\hline
\end{tabular}

Statistical significant values are displayed in bold writing. RC, radical cystectomy; LOS, length of stay.

LOS $[16,23]$, while German hospitals are fined with financial discounts if the LOS is below the lower limit of 6 days [24]. Subsequently, timely postoperative discharge and continuous ambulatory care are enforced stronger in the US healthcare system [25], while German hospitals are more likely to monitor patients in an inpatient setting until autonomous provision is guaranteed.

A recent study on SEER-Medicare linked data from 2002 to 2011 reported that only approximately $20 \%$ of patients with muscle-invasive bladder cancer in the United States underwent RC [26]. While 30\% received radiation or radio-chemotherapy, 50\% were left without curative treatment. Although no comparable study data for Germany exists, we can approximate that the total num- ber of RC for bladder cancer in $2011(n=6,928)$ account for $86 \%$ of the total incidence of stage $\geq \mathrm{T} 1$ bladder cancer cases in Germany [1]. Therefore, an estimated $70-80 \%$ of eligible patients might have undergone RC in Germany in 2011 leaving a small percentage of patients for nonsurgical or missing curative treatment. Comparable differences in the utilization of radiotherapy in the United States and Germany were currently reported for treatment of prostate cancer [27]. Lower implementation rates of RC in the United States might imply enforced positive patient selection with younger and healthier patients for surgery. This might pose a relevant explanation for lower mortality and transfusion rates and reduced LOS in the United States $[4,6]$. 
There is growing evidence for the positive impact of higher caseload volumes and surgical experience on postoperative outcomes following complex oncologic surgery [10-13], which is mirrored by our findings on multivariate analysis. Centralizing complex oncologic surgery has been repeatedly discussed [28] and recommended in international guidelines $[29,30]$. Some regions started this process with promising results $[12,28$, 31]. In the United States, the relatively high share of RC in low-volume hospitals slightly decreased while increasing by roughly tenfold in high-volume hospitals until 2011, demonstrating a trend toward centralization of RC. Respective tendencies in Germany were not statistically significant although the share of RC in low-volume hospitals ( $<4$ cases annually) was constantly below $1 \%$ during that time.

To our knowledge, this is the first study comparatively analyzing current trends of in-hospital outcomes after RC in the United States and Germany using population based data from a period of 9 years. We demonstrated, that vast divergences concerning in-hospital outcomes in both countries. A relevant share of the causes for this observation might consist in major differences of both national healthcare systems.

The primary limitation of our study consists in the lack of clinical information representing a possible source of bias. Also, histological parameters of the tumor are not included, which makes it impossible to stratify the outcomes for tumor staging or grading. Although billing data is highly accurate, it relies on correct coding by the hospital. Identification of patients or single hospitals is prohibited due to anonymization-regulations. Additional hospital stays of the same patient are not assignable and outcomes can be determined only for the inpatient stay. In the NIS coding system, hospital size and location are categorized by a complex algorithm, which is not transferable to the German situation, but we applied a comparable classification mechanism. We anticipated known differences in content or coding properties relevant to our analysis and adjusted the statistical assessment accordingly. In view of the large number of cases, our main results should nevertheless be very robust.

\section{Conclusion}

High annual RC caseload was associated with reduced mortality and LOS in the United States and Germany. Mortality and transfusion rates in the United States are significantly lower. A much shorter LOS, stronger patient selection, and higher adoption of RARC in the United States might explain these differences to some extent. Shorter LOS in the United States following RC might indicate possibilities to enhance cost-effectiveness and surgical frequency in Germany. A trend of centralization for RC was only seen for the United States during the study period.

\section{Acknowledgments}

Data source: US NIS and German research data center of the federal statistical office, DRG-statistics 2006-2014, own calculations.

We thank Stefanie Uhrich and Melanie Scheller for supporting data retrieval. Part of this study was presented at the Annual Meeting of the American Urologists' Association in 2017.

\section{Ethics Statement}

This study was conducted in accordance with the Declaration of Helsinki in its latest version. This article does not contain any studies with animals performed by any of the authors. Analyzed data were completely anonymized and derived from established databases with rigorous data protection measures. Hence, informed consent was not required.

\section{Disclosure Statement}

Dr. Johannes Huber reports having received personal fees from Amgen and Janssen, grants and non-financial support from Intuitive Surgical and Takeda, outside the submitted work. All other authors declare that there are no conflicts of interest to disclose.

\section{Funding Sources}

Med-Drive Grant of the medical faculty Carl Gustav Carus TU Dresden. (Grant-number: 60.356).

\section{Author Contribution}

All authors whose names appear on the submission have contributed sufficiently to the scientific work and therefore share collective responsibility and accountability for the results. C.G.: Project development, data collection, data analysis, manuscript writing. R.K.: Data collection, data analysis. M.B.: Project development, manuscript writing. A.B.: Data collection, manuscript editing. M.P.W.: Project development, manuscript editing. J.H.: Project development, manuscript writing/editing. 


\section{References}

1 Robert Koch Institute (ed) and the Association of Population-based Cancer Registries. Cancer in Germany 2011/2012, Berlin.

2 Siegel RL, Miller KD, Jemal A. Cancer statistics, 2016. CA Cancer J Clin. 2016 Jan-Feb; 66(1):7-30.

3 Aziz A, May M, Burger M, Palisaar RJ, Trinh QD, Fritsche HM, et al.; PROMETRICS 2011 research group. Prediction of 90-day mortality after radical cystectomy for bladder cancer in a prospective European multicenter cohort. Eur Urol. 2014 Jul;66(1):156-63.

4 Froehner M, Brausi MA, Herr HW, Muto G, Studer UE. Complications following radical cystectomy for bladder cancer in the elderly. Eur Urol. 2009 Sep;56(3):443-54.

5 Kader AK, Richards KA, Krane LS, Pettus JA, Smith JJ, Hemal AK. Robot-assisted laparoscopic vs open radical cystectomy: comparison of complications and perioperative oncological outcomes in 200 patients. BJU Int. 2013 Aug;112(4):E290-4.

6 Roghmann F, Sukumar S, Ravi P, Trinh VQ, Meskawi M, Ghani KR, et al. Radical cystectomy in the elderly: national trends and disparities in perioperative outcomes and quality of care. Urol Int. 2014;92(1):27-34.

7 Waingankar N, Mallin K, Smaldone M, Egleston BL, Higgins A, Winchester DP, et al. Assessing the relative influence of hospital and surgeon volume on short-term mortality after radical cystectomy. BJU Int. 2017 Aug; 120(2):239-45

8 Gierth M, Zeman F, Denzinger S, Vetterlein MW, Fisch M, Bastian PJ, et al. Influence of Body Mass Index on Clinical Outcome $\mathrm{Pa}$ rameters, Complication Rate and Survival after Radical Cystectomy: Evidence from a Prospective European Multicentre Study. Uro. Int. 2018;101(1):16-24.

9 Zattoni F, Palumbo V, Giannarini G, Crestani A, Kungulli A, Novara G, et al. Perioperative Outcomes and Early Survival in Octogenarians Who Underwent Radical Cystectomy for Bladder Cancer. Urol Int. 2018;100(1):13-7.

10 Barocas DA, Mitchell R, Chang SS, Cookson MS. Impact of surgeon and hospital volume on outcomes of radical prostatectomy. Urol Oncol. 2010 May-Jun;28(3):243-50.

11 Groeben C, Koch R, Baunacke M, Wirth MP, Huber J. High volume is the key for improving in-hospital outcomes after radical prostatectomy: a total population analysis in Germany from 2006 to 2013 . World J Urol. 2017 Jul;35(7):1045-53.
12 Hounsome LS, Verne J, McGrath JS, Gillatt DA. Trends in operative caseload and mortality rates after radical cystectomy for bladder cancer in England for 1998-2010. Eur Urol. 2015 Jun;67(6):1056-62.

13 Nielsen ME, Mallin K, Weaver MA, Palis B, Stewart A, Winchester DP, et al. Association of hospital volume with conditional 90-day mortality after cystectomy: an analysis of the National Cancer Data Base. BJU Int. 2014 Jul; 114(1):46-55.

14 Knox ML, El-Galley R, Busby JE. Robotic versus open radical cystectomy: identification of patients who benefit from the robotic approach. J Endourol. 2013 Jan;27(1):40-4.

15 Bochner BH, Dalbagni G, Sjoberg DD, Silberstein J, Keren Paz GE, Donat SM, et al. Comparing Open Radical Cystectomy and Robotassisted Laparoscopic Radical Cystectomy: A Randomized Clinical Trial. Eur Urol. 2015 Jun;67(6):1042-50.

16 Ridic G, Gleason S, Ridic O. Comparisons of health care systems in the United States, Germany and Canada. Mater Sociomed. 2012; 24(2):112-20

17 Groeben C, Koch R, Baunacke M, Schmid M, Borkowetz A, Wirth MP, et al. Urinary Diversion After Radical Cystectomy for Bladder Cancer: comparing Trends in the US and Germany from 2006 to 2014. Ann Surg Oncol. 2018 Nov;25(12):3502-9.

18 Chang SL, Kibel AS, Brooks JD, Chung BI. The impact of robotic surgery on the surgical management of prostate cancer in the USA. BJU Int. 2015 Jun;115(6):929-36.

19 Groeben C, Koch R, Baunacke M, Wirth MP Huber J. Robots drive the German radical prostatectomy market: a total population analysis from 2006 to 2013. Prostate Cancer Prostatic Dis. 2016 Dec;19(4):412-6.

20 Carson JL, Grossman BJ, Kleinman S, Tinmouth AT, Marques MB, Fung MK, et al.; Clinical Transfusion Medicine Committee of the AABB. Red blood cell transfusion: a clinical practice guideline from the AABB*. Ann Intern Med. 2012 Jul;157(1):49-58.

21 Bundesarztekammer. Querschnitts-Leitlinien (BAK) zur Therapie mit Blutkomponenten und Plasmaderivaten. In: Bundesarztekammer, editor. Vorstand der Bundesarztekammer; 2014.

22 Davis K, Ballreich J. Equitable access to carehow the United States ranks internationally. N Engl J Med. 2014 Oct;371(17):1567-70.
23 Leow JJ, Cole AP, Seisen T, Bellmunt J, Mossanen M, Menon M, et al. Variations in the Costs of Radical Cystectomy for Bladder Cancer in the USA. Eur Urol. 2017 Aug;S03022838(17)30640-1.

24 Knoll M, Otte I, Salloch S, Ruiner C, Kruppa E, Vollmann J. ["Something humane has been lost". Re-evaluation of the attitudes of senior physicians towards the G-DRG System - a qualitative normative analysis]. Z Evid Fortbild Qual Gesundhwes. 2018 Apr;131-132: 60-5.

25 Meyer CP, Hollis M, Cole AP, Hanske J, O'Leary J, Gupta S, et al. Complications Following Common Inpatient Urological Procedures: Temporal Trend Analysis from 2000 to 2010. Eur Urol Focus. 2016 Apr;2(1):3-9.

26 Williams SB, Huo J, Chamie K, Hu JC, Giordano SH, Hoffman KE, et al. Underutilization of Radical Cystectomy Among Patients Diagnosed with Clinical Stage T2 Muscle-invasive Bladder Cancer. Eur Urol Focus. 2017 Apr; 3(2-3):258-64.

27 Hager B, Kraywinkel K, Keck B, Katalinic A, Meyer M, Zeissig SR, et al. Integrated prostate cancer centers might cause an overutilization of radiotherapy for low-risk prostate cancer: A comparison of treatment trends in the United States and Germany from 2004 to 2011. Radiother Oncol. 2015 Apr;115(1):905.

28 Hermans TJ, Fransen van de Putte EE, Fossion LM, Werkhoven EV, Verhoeven RH, van Rhijn BW, Horenblas S. Variations in pelvic lymph node dissection in invasive bladder cancer: A Dutch nationwide populationbased study during centralization of care. Urol Oncol 2016;34:532 e537-532 e512.

29 Abdollah F, Sun M, Schmitges J, Thuret R, Djahangirian O, Jeldres C, et al. Surgical caseload is an important determinant of continent urinary diversion rate at radical cystectomy: a population-based study. Ann Surg Oncol. 2011 Sep;18(9):2680-7.

30 Witjes JC, Cowan NC, De Santis M, Gakis G, James N, Lebret T. Guidelines on Muscle-invasive and Metastatic Bladder Cancer. European Association of Urology 2017.

31 Afshar M, Goodfellow H, Jackson-Spence F, Evison F, Parkin J, Bryan RT, et al. Centralisation of radical cystectomies for bladder cancer in England, a decade on from the 'Improving Outcomes Guidance': the case for super centralisation. BJU Int. 2018 Feb;121(2):217-24. 